Column Editor - Debra Paul, OTR/L

The journey of having an infant in the intensive care setting is a life altering event; one that many parents are not anticipating and will not soon forget. COVID-19 and the challenges associated with it have had a profound impact on infants and families whose life starts in the NICU. We have heard from our NICU colleagues across the world regarding policy changes in the face of the pandemic including restrictions in parents being with their infant which of course, has compounded the overwhelming stress and sadness parents experience. In this article, Lindsay Gilmore shares the story of her family's experience in the NICU at the onset of the pandemic and how they navigated it with courage and hope.

\title{
Heartbreak and Hope during the Pandemic
}

Lindsay Gilmore

$\mathrm{O}$ ur pregnancy story begins as most do. Kyle and I became pregnant just a few months after officially deciding that we were ready for the new adventure of a child. We felt overly excited despite the typical dose of apprehension. My pregnancy consisted of the average morning sickness, body aches, and back pain; without fail all my symptoms were affirmed by the pregnancy apps that I would reference religiously. What was not average was the rise of a pandemic in my third trimester, one we have now all been impacted by in countless ways. At first, for us, this simply meant that we could hunker down together at home. I could do my best to teach middle schoolers online and my husband was being paid to stay home for a short time from his government job. This allowed us to do slow jogs together, cook yummy food, and prepare the nursery for the arrival of our sweet baby. We both felt quite happy in our new quarantine and I felt lucky for the chance to succumb to my aching and tired limbs. On April 1st, 2020, week 31 of pregnancy, we had a perfectly routine ultrasound, except for the new personal protective equipment (PPE) that our doctors and nurses were brandishing, of course. It was just two days later that the pregnancy took a startling turn.

The baby inside of me, which we had yet to know was a boy or a girl, was quite the acrobat. Our baby moved predictably, and I could trust that around 7:30 each evening I would feel a fury of movement. I will always be so grateful for this predictability, as it is one of many things that would come to save the life of our sweet baby girl. Come Thursday evening, I didn't feel the baby move as I typically would, but I did feel a series of irregular Braxton Hicks contractions. I assumed that the lack of fetal movement was simply replaced by another typical sensation. The next day, while remote teaching on Zoom (video conferencing), I recall pausing to notice and wonder what was keeping my baby so quiet, as I had yet to feel any noticeable movement that day. While I knew that fetal movement often decreased later in term, I nevertheless felt unsettled about the lack of motion. Something didn't feel right. The day went on as I played mental ping pong, alternating between feeling as if I was being overly dramatic, and then feeling genuinely concerned. Come nine pm that night, after trying everything Google told me to-- jumping jacks, chocolate milk, a bright light, talking loudly, glass after glass of

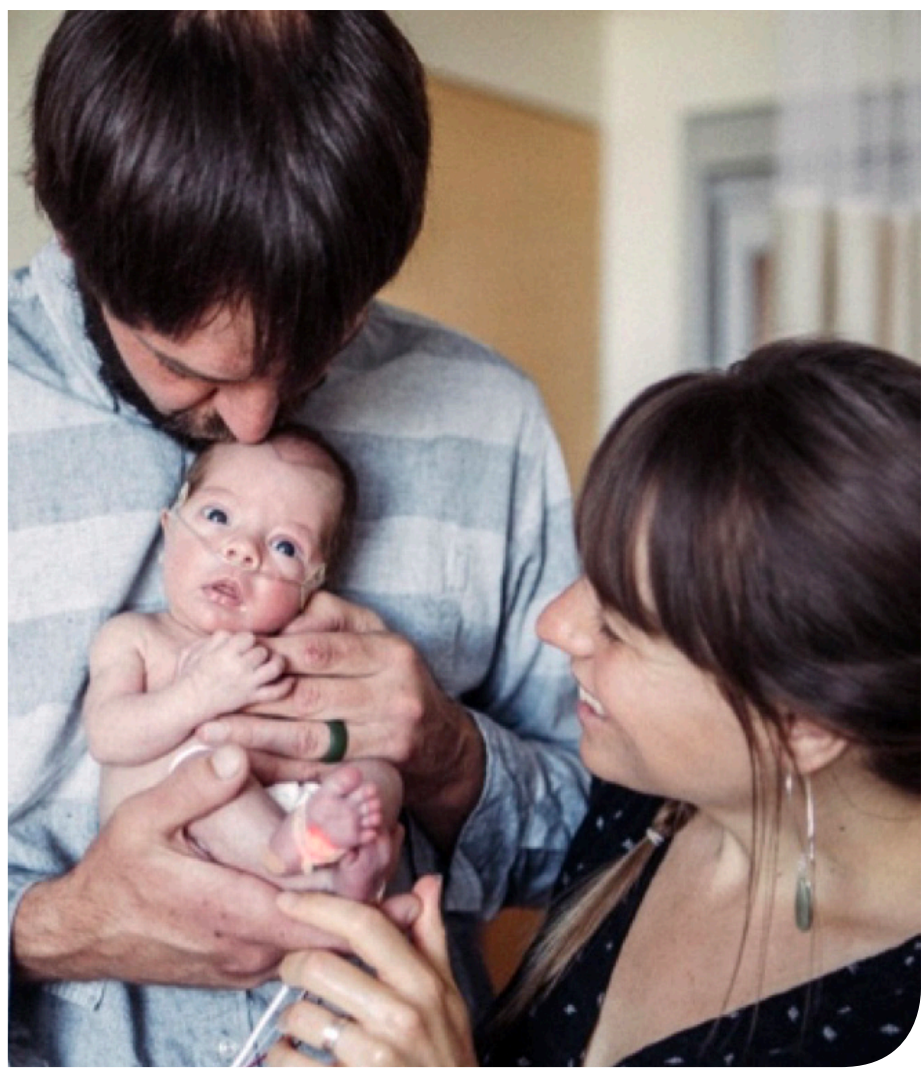

Nearing the end of our NICU journey at 40 weeks.

juice, I still felt nothing and finally decided to call my provider. Thankfully, the on-call obstetrician (OB) that night listened intently and wasted no time validating my concern. Her responsiveness was yet another life saving measure. She later told me that knowing what she knows now, she guesses that our baby girl had only about two more hours of life left in utero, had we not quickly found her a way out.

The next few hours were spent getting checked in to the local hospital and assessing the situation. What Kyle and I deemed routine protocol, ultimately led to the appearance of my $\mathrm{OB}$ and a team of nurses, dressed for surgery. Typically, medical emergencies would be flown down to Denver, as we were in a small mountain community without the same level of care, 
but it was decided that our baby was in immediate danger and we didn't have the necessary time for travel. Instead, Kyle and I were informed that a Children's Hospital Colorado NICU Flight team would arrive to meet our baby upon birth. At 1:51 am on April 3rd, Luka Lorene, was born extremely ill at 3 pounds, 5 ounces (1587 gram). With a low hematocrit of 6 (g/DL) and a low hemoglobin of 2, (g/DL) she had an acute loss of blood and oxygen. As it turns out, the NICU Flight team was significantly delayed due to weather, and so the team at our local hospital stepped up and helped to maintain our daughter's life. After an incredibly traumatic few hours, the NICU team arrived and Luka was finally transported down to the Children's Hospital in Aurora, Colorado. Kyle left to meet Luka as she arrived at the hospital, and our NICU journey began.

The next 24 hours were the most difficult of our lives as we fielded conversations about how sick our daughter was and heard expectations of her outcomes-- these were face to face conversations for Kyle, and communicated over the phone to me, as I remained in a different county. There was immediate confusion about why Luka was so sick and what went so wrong in utero. As there was no obvious explanation, doctors wondered if perhaps COVID-19 was to blame. She and I were tested but had to wait some time for results. When we received word that Luka wasn't expected to make it through the night, there was back and forth discussions about whether or not it would be safe for me to be reunited with her. A plan was made to discharge me under the premise that I was infected with COVID-19, and so I left in the hands of my parents to be driven to Denver 15 hours after my emergency C-Section. I arrived at the "dirty hall"-- the space that was reserved for those suspected of COVID-19 and took in the harsh sights and sounds of the NICU. The following hours continued to be a blur, but it was a comfort to touch the arms and legs of my sweet girl through the plastic walls of her isolette. The myriad of bells and alarms continued to ring in our ears as we watched many people come in and out of the room, managing the countless wires and tubes coming from her body and at times, attending to us. At the time, I didn't know who these people were, but I now know it was her exceptional team of doctors, nurses, respiratory therapists, ultrasound techs, nurse practitioners, social workers, specialists, and the like. It looked as

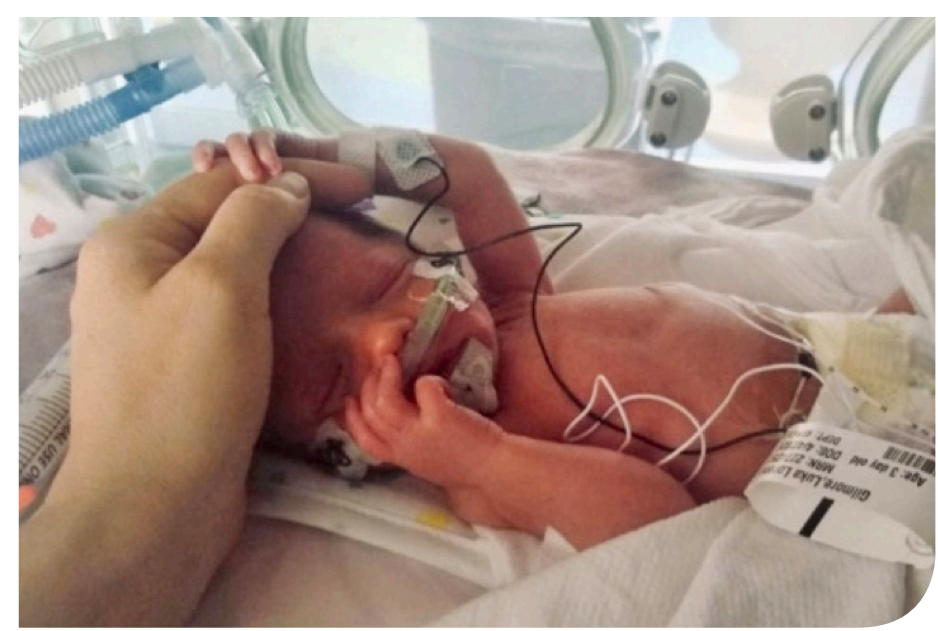

Luka at one week of age

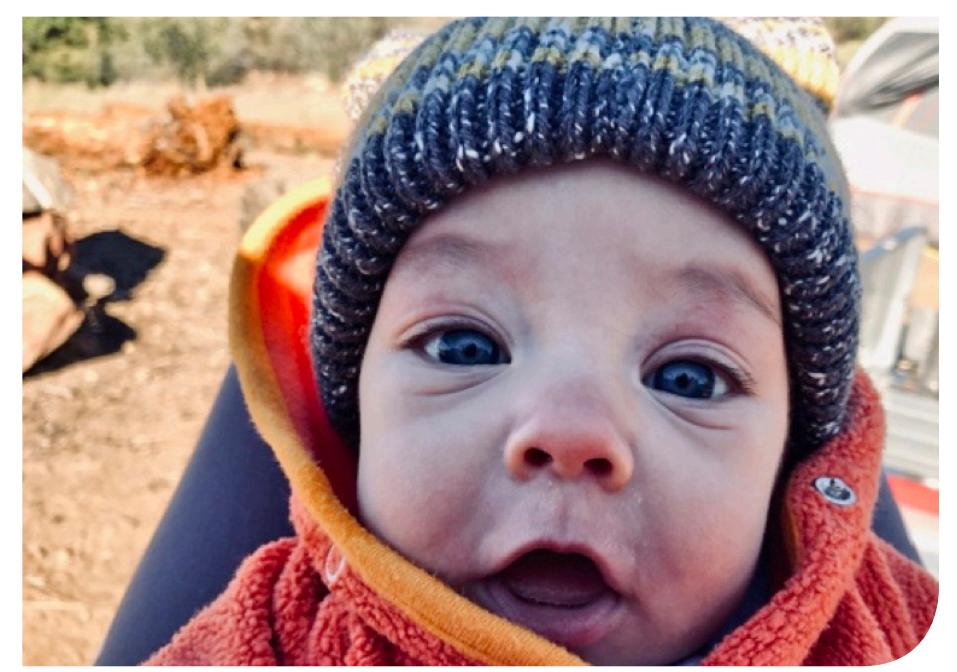

Luka at 5 months, celebrating being oxygen free by going on her first camping trip!

if we were in outer space, as they had PPE from head to toe and this being early April, not even masks felt commonplace. It was all so out of body, and beyond terrifying.

Being the fighter she is, Luka made it through the night. While her organs began to rebound, there continued to be trepidation about her outcomes. Given that she was without oxygen for seven and a half minutes at birth, we were prepared for significant impact and insult to her brain. We were warned that she may not walk, talk, or play. Miraculously, her brain magnetic resonance imaging (MRI) scan a week later showed only mild brain trauma and she had no signs of seizures-- we rejoiced! Within one week, she had weaned off her ventilator, was opening her eyes, and her organs all seemed to be improving their function with every day. While we felt so encouraged by Luka's progress, the growing impact of COVID-19 was creeping into the hospital and complicating an already difficult time.

Six days after we arrived at the NICU, the hospital enacted a one visitor per room policy. This was hard to swallow, as neither Kyle nor I could imagine losing time near Luka or each other. We had incredible support and advocacy from our NICU care team, and they advocated for us to receive an exception for the first eight days while I continued to heal from my Caesarean section. This was granted. Because we lived at a distance from the hospital, we had been spending each night either in a hospital sleeper room or the hospital room itself, and so moving forward we were allowed to both be present in the hospital at the same time, just not together in Luka's hospital room. While this arrangement still created significant logistical issues and felt lonely and isolating, we felt so lucky for the exceptions. Thankfully, this policy ended about a month later, and its end was met with great relief.

The days transitioned to weeks, and eventually the weeks transitioned to months. We found our routines in the NICU. I became consumed with pumping and increasing my milk supply, asking for lactation support as often as I could. Kyle became a master at coordinating our daily meals, keeping my water bottle full, and doing his part in skin to skin. We were solely focused on doing everything we could for Luka and relished the opportunity to hold her for hours at a time, once we were finally able to do so. There were many lows-- mastitis, a mysterious infection 
in Luka's gland, disagreeing specialists, new IV's (intravenous therapy), bradycardia events, and transfusions, but the highs overwhelmed them all. We delighted in her growth and the continued good news about her development. Her occupational and physical therapy visits left us most encouraged; we appreciated the tangible advice and skills that we received from her OT and PT specialists, as we always felt more empowered to support Luka.

As Luka's rounds began to occur later in the day and at a much more rapid pace, we knew that we were nearing the end of our NICU stay. After 59 nights of sleeping at Children's Hospital, it was finally time to leave. We were overwhelmed with joy that Luka was healthy and ready to come home, but there was a deep sadness over saying goodbye to the people that had seen us through the most difficult experience of our lives. Our gratitude for this team is without measure. Their listening and encouragement, their secret hugs (in the time of COVID-19), and their expertise left us in awe on a daily basis. We only just wish we were more acquainted with their beautiful faces; after so much time spent together, it was always a fun surprise if we caught a glimpse of anything more than their eyes below their masks. Another pandemic reality.

We still do not have answers about what went wrong in utero. There are theories-- Luka has a blood disorder, we experienced a fetomaternal hemorrhage, or she was on her way to a still-birth. The doctors still maintain that it's a relative mystery. The best explanation came from one of our favorite Neonatal Nurse Practitioners when she said, "consider yourself hit by

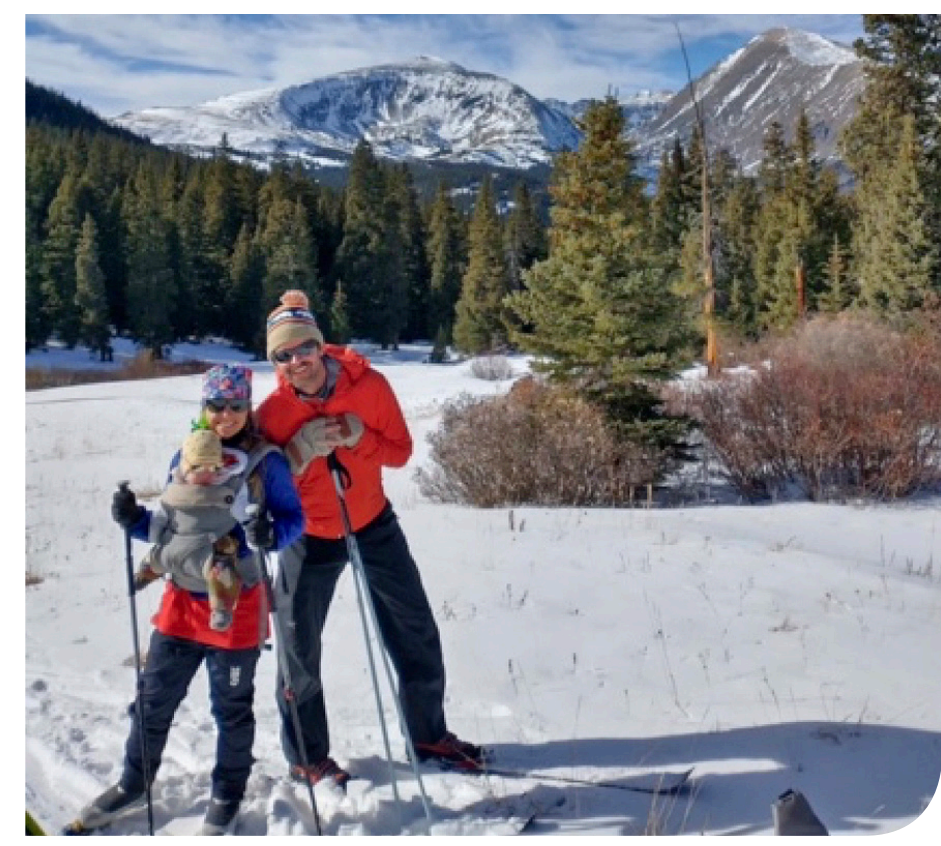

Luka is now a happy 9 months and the Gilmores are living their best life in the mountains of Breckenridge, Colorado.

lightning." In the same way, we understand that it was only with answered prayers and pure luck that today, Luka is thriving. We know full well that many NICU stories are without a happy ending and so we are beyond thankful that our prayers were answered in this way. For now, we treasure Luka's pure existence and feel blessed to be her parents.

\section{WORLD NIDCAP DAY MARCH 20 TH 2021}

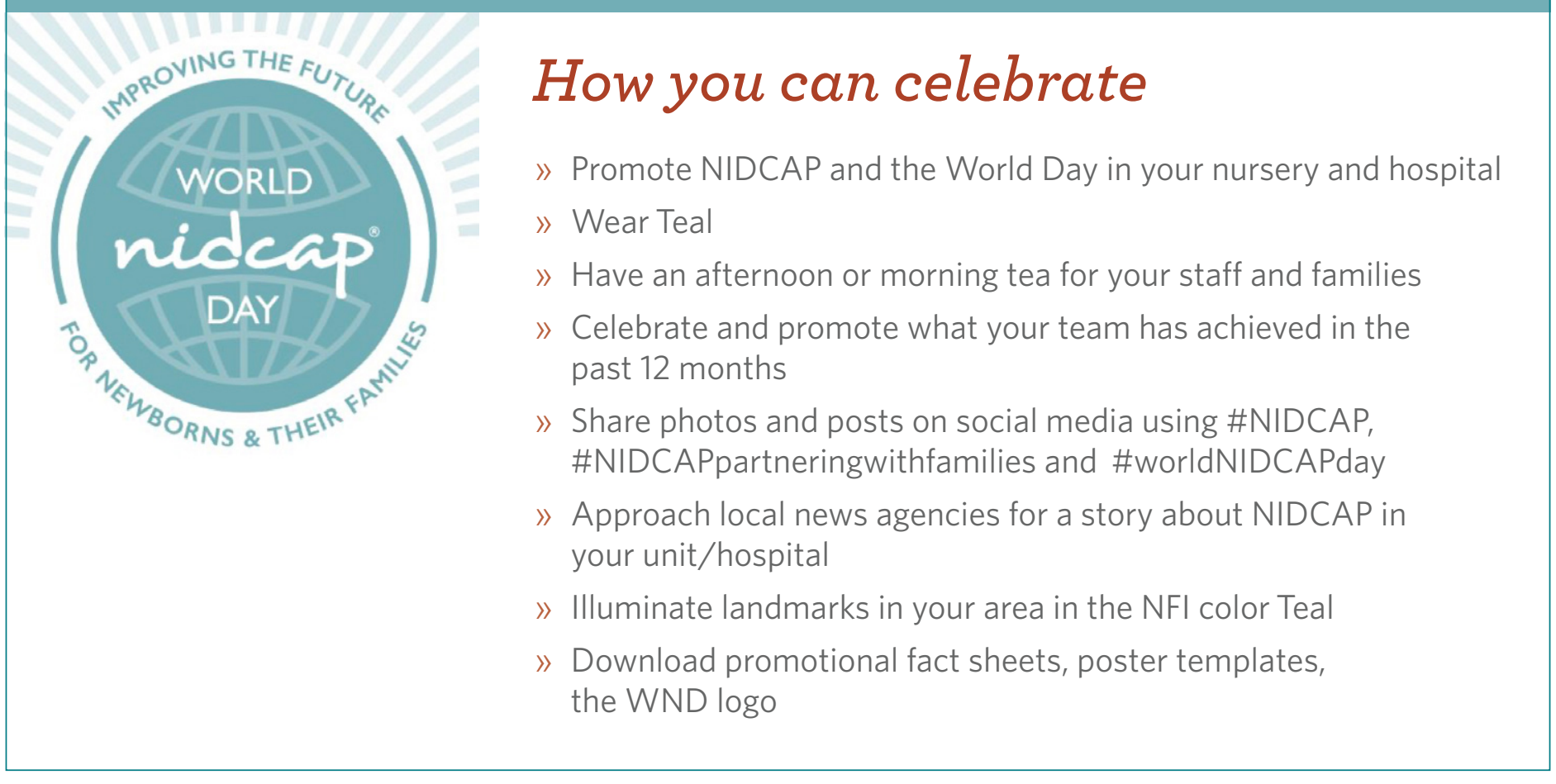

